This is the author's final, peer-reviewed manuscript as accepted for publication. The publisher-formatted version may be available through the publisher's web site or your institution's library.

\title{
Simulation of Electromechanical Interactions of Permanent- Magnet Direct-Drive Wind Turbines Using the FAST Aeroelastic Simulator
}

David S. Ochs, Ruth Douglas Miller, and Warren N. White

\section{How to cite this manuscript}

If you make reference to this version of the manuscript, use the following information:

Ochs, D. S., Miller, R. D., \& White, W. N. (2014). Simulation of electromechanical interactions of permanent-magnet direct-drive wind turbines using the fast aeroelastic simulator. Retrieved from http://krex.ksu.edu

\section{Published Version Information}

Citation: Ochs, D. S., Miller, R. D., \& White, W. N. (2014). Simulation of electromechanical interactions of permanent-magnet direct-drive wind turbines using the fast aeroelastic simulator. IEEE Transactions on Sustainable Energy, 5(1), 2-9.

Copyright: @ 2013 IEEE

Digital Object Identifier (DOI):10.1109/TSTE.2013.2269681

Publisher's Link: http://ieeexplore.ieee.org/xpls/abs all.jsp?arnumber=6570553\&tag=1

This item was retrieved from the K-State Research Exchange (K-REx), the institutional repository of Kansas State University. K-REx is available at http://krex.ksu.edu 


\title{
Simulation of Electromechanical Interactions of Permanent-Magnet Direct-Drive Wind Turbines using the FAST Aeroelastic Simulator
}

\author{
David S. Ochs, Graduate Student Member, IEEE, Ruth Douglas Miller, Senior Member, IEEE, and \\ Warren N. White
}

\begin{abstract}
Two detailed models of permanent-magnet directdrive (PMDD) wind turbines with full converters are presented in this paper: one for a $10 \mathrm{~kW}$ turbine, and one for a $5 \mathrm{MW}$ turbine. The models are verified by comparing the power curves found through simulation with field test data. Other results are also presented that show the unprecedented detail of the models. The mathematical representations include switching models for the full converters, circuit models for permanent-magnet synchronous generators, realistic aerodynamics, tower and blade vibrations, and many other variables. The models are valuable tools for wind turbine design and research and can be used for a wide range of purposes including control system design, sensitivity analysis, and interactions between the electrical and mechanical parts of a PMDD wind turbine. Simulation of the models is carried out in the MATLAB/Simulink environment using the FAST aeroelastic simulator.
\end{abstract}

Index Terms-FAST, permanent-magnet synchronous generator (PMSG), pulse width modulated (PWM) converters, wind energy

\section{INTRODUCTION}

$\mathrm{W}$ IND energy penetration in the world's electric grids has skyrocketed in recent years. The field of wind power engineering has come a long way since the first variable-speed wind turbines in the United States came online in the 1970's [1]. As demand for wind turbines grows, so too does demand for useful tools with which to design and test them. A detailed MATLAB/Simulink model was recently published for photovoltaic panels, however, no corresponding tool for permanent-magnet wind turbines currently exists [2]. The major contribution of this work is the detailed development of comprehensive models of a residential-scale and a utility-scale permanent-magnet direct drive $(P M D D)$ wind turbines. Simulations of these models provide realistic results for the electrical, mechanical, and aerodynamic parts of a wind turbine. Therefore, the models can be used in the design process of a wind turbine shown in Fig. 1. The models are novel tools that can be easily reproduced and can be used to

D.S. Ochs is with the Electrical and Computer Engineering Department, Kansas State University, Manhattan, KS 66506 USA (email: ochs.dave@gmail.com).

R.D. Miller is with the Electrical and Computer Engineering Department, Kansas State University, Manhattan, KS 66506 USA (email: rdmiller@ksu.edu).

W.N. White is with the Mechanical and Nuclear Engineering Department, Kansas State University, Manhattan, KS 66506 USA (email: wnw @ ksu.edu).

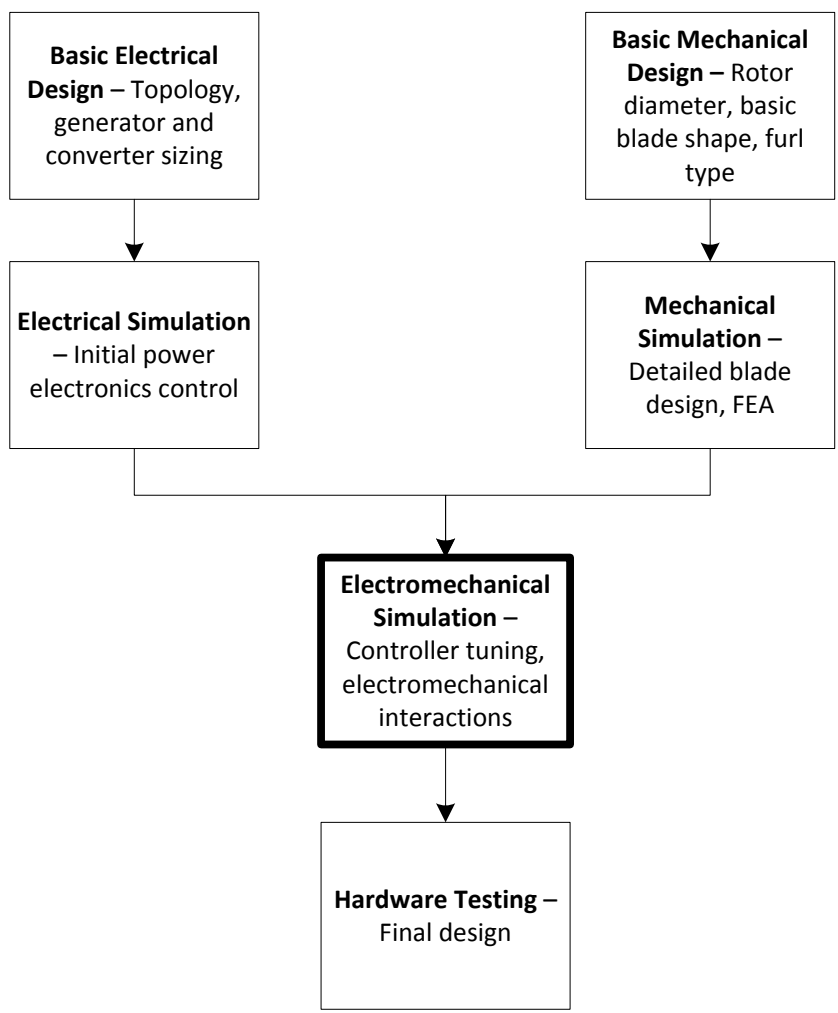

Fig. 1 High level wind turbine design process with electromechanical simulations highlighted.

design and study many different aspects of both large and small wind turbines, including control systems and electromechanical interactions.

There has been significant interest in electromechanical simulations of variable speed wind turbines in recent years. Fadaeinedjad et al. and Beltran et al. used FAST to investigate the mechanical effects of electrical faults on doubly-fed induction generator (DFIG)-based wind turbines [3] [4]. Both used high-level models for the turbine's electrical systems. Krishna and Reeba reported executing electromechanical simulations using FAST with a switched-reluctance generator [5]. Zhang et al. used a torque-speed equation to model a permanent-magnet synchronous generator $(P M S G)$ as part of FAST simulations for control design [6]. Corbus and Meadors first modeled the $10 \mathrm{~kW}$ system that is the basis of the one in this paper in FAST with a simple torque-speed curve as the generator model [7]. Hemeida et al. modeled a PMSG turbine 
with a full converter but did not compare their results to field data [8]. None of these workers have produced a complete model of the PMDD with a full converter.

This work begins with a description of each system being modeled. Next, details on the models and control designs for each generator, active rectifier, voltage source inverter (VSI), and LCL filter are presented. Results are then presented that show the validity of the models as well as the high level of detail they are capable of simulating. Conclusions are then drawn and ideas for future work are given.

\section{SYSTEM DESCRIPTION}

\section{A. Electrical System}

Variable-speed wind turbines have two major advantages over constant-speed ones: they are capable of operating over a wider range of speeds and they can provide reactive power support to the grid. There are two prevailing topologies for variable-speed wind turbines today: the DFIG with partial power converter and the PMSG with full power converter. The direct-drive PMSG schematic is shown in Fig. 2. The topology shown in Fig. 2 is called a back-to-back or full converter and it consists of an active rectifier, a DC link capacitor, a VSI, an LCL filter, and a transformer. This topology is prevalent in PMDD wind turbines designs [9] [10]. Relevant information on the electrical models for each system is given in Table I. All of the electrical components have been modeled in Simulink with blocks from the SimPowerSystems toolbox.

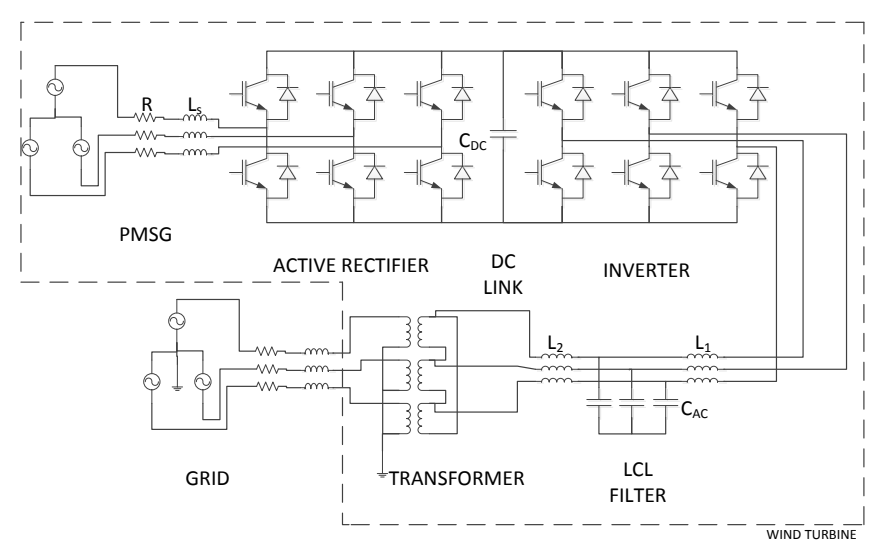

Fig. 2. Electrical system model. The model includes a PMSG, an active rectifier, a DC link capacitor, a 3-phase inverter, a LCL filter, a transformer, and the grid.

TABLE I

ELECTRICAL MODEL SUMMARY

\begin{tabular}{|c|c|c|}
\hline Parameter & $10 \mathrm{~kW}$ System & 5 MW System \\
\hline Nominal grid voltage & $208 \mathrm{~V}$ & $34.5 \mathrm{kV}$ \\
\hline Nominal PMSG voltage & $260 \mathrm{~V}$ & $690 \mathrm{~V}$ \\
\hline $\mathrm{C}_{\mathrm{DC}}$ & $600 \mu \mathrm{F}$ & $2000 \mu \mathrm{F}$ \\
\hline PMSG poles & $28-36$ & 18 \\
\hline PMSG stator resistance & $0.05-0.2 \Omega$ & $0.476 \mathrm{~m} \Omega$ \\
\hline PMSG synchronous inductance & $1-4 \mathrm{mH}$ & $0.177 \mathrm{mH}$ \\
\hline IGBT forward voltage drop & $2.0 \mathrm{~V}$ & $2.0 \mathrm{~V}$ \\
\hline Diode forward voltage drop & $1.0 \mathrm{~V}$ & $1.0 \mathrm{~V}$ \\
\hline IGBT conducting resistance & $55 \mathrm{~m} \Omega$ & $7 \mathrm{~m} \Omega$ \\
\hline IGBT fall time & $70 \mathrm{~ns}$ & $200 \mathrm{~ns}$ \\
\hline Transformer turns ratio & $2.308: 1$ & $1: 53.0769$ \\
\hline Back EMF constant & $1-3 \mathrm{~V}_{\text {peak }, \mathrm{LL}} / \mathrm{Hz}$ & $1.724 \mathrm{kV}_{\text {peak }, \mathrm{LL}} / \mathrm{Hz}$ \\
\hline
\end{tabular}

TABLE II

AEROELASTIC MODEL SUMMARY

\begin{tabular}{|l|l|l|}
\hline Parameter & 10 kW Turbine & 5 MW Turbine \\
\hline Rotor diameter & $7 \mathrm{~m}$ & $123 \mathrm{~m}$ \\
\hline Nacelle mass & $260.5 \mathrm{~kg}$ & $240,000 \mathrm{~kg}$ \\
\hline Nacelle inertia & $39.81 \mathrm{~kg} \mathrm{~m}^{2}$ & $2,6078,9000 \mathrm{~kg} \mathrm{~m}^{2}$ \\
\hline Generator inertia & $0.5 \mathrm{~kg} \mathrm{~m}^{2}$ & $534.116 \mathrm{~kg} \mathrm{~m}^{2}$ \\
\hline Hub inertia & $7.71 \mathrm{~kg} \mathrm{~m}^{2}$ & $115,926 \mathrm{~kg} \mathrm{~m}^{2}$ \\
\hline Blade nodes for BEM & 15 & 17 \\
\hline Blade mass & $21.7724 \mathrm{~kg}$ & $17,740 \mathrm{~kg}$ \\
\hline
\end{tabular}

\section{B. Wind Turbine Models}

The small wind turbine model used in this work is a combination of the Small Wind Research Turbine (SWRT) developed by the National Renewable Energy Laboratory (NREL) and the Bergey Excel 10 as it was produced in 2012. The SWRT is a modified version of the Bergey Excel 10 as it was produced in 2005 [7]. It is a 3-bladed, horizontal axis, upwind turbine with passive yaw. Since 2005 there have been several upgrades to the turbine, including a new PMSG and longer blades [11]. A proprietary model from Bergey Windpower was used for the generator parameters, and, as a result, ranges rather than exact values for those quantities are provided in Table I. The tower model used was developed by NREL for use in testing a research turbine. Detailed information on the $11.5 \mathrm{~m}$ tower can be found in [12].

The 5 MW turbine's mechanical and aeroelastic models, including a $90 \mathrm{~m}$ tower, are from of the NREL $5 \mathrm{MW}$ machine [13]. The NREL $5 \mathrm{MW}$ turbine is not a direct model of any one turbine, but it is based heavily on the REpower $5 \mathrm{MW}$. The model in this paper, including the full electrical model summarized in Table I, is compared to the REpower machine in Section V.

The key parameters of the mechanical model for each system are given in Table II.

Four different public domain design codes distributed by NREL were used in developing the models and in their simulation: Modes for the mode shapes of the towers, TurbSim for 3-dimensional turbulent wind, AeroDyn for aerodynamic simulations, and FAST for aeroelastic and mechanical simulations [14] [15] [16] [17].

\section{GENERATOR CONTROL}

The PMSG in each turbine model is represented by the well-known circuit model in a reference frame attached to the machine's rotor- namely [18],

$$
\begin{gathered}
v_{d}=R i_{d}-p \omega_{r} L_{q} i_{q}+L_{d} \frac{d i_{d}}{d t}, \\
v_{q}=R i_{q}+p \omega_{r}\left(L_{d} i_{d}+\psi\right)+L_{q} \frac{d i_{q}}{d t}, \\
\tau_{e}=\frac{3}{2} p\left(i_{d} i_{q}\left(L_{d}-L_{q}\right)+\psi i_{q}\right),
\end{gathered}
$$

and

$$
\omega_{r}=\frac{d \theta_{r}}{d t}
$$

where subscript " $d$ " denotes direct-axis quantities, subscript 
" $q$ " denotes quadrature-axis quantities, and subscript " $r$ " denotes rotor quantities. $R$ is the per-phase stator resistance, $p$ is the number of pole pairs, $\omega_{r}$ is the rotor speed in $\mathrm{rad} / \mathrm{s}$ and $\psi$ is the flux established by the permanent-magnets in webers. Equations (1) - (3) assume that positive currents flow into the PMSG. Negative generator torque $\left(\tau_{\mathrm{e}}\right)$ corresponds to operation as a generator. It is assumed that $L_{d}=L_{q}=L_{s}$, where $L_{s}$ is the synchronous inductance, so (3) may be rewritten as

$$
\tau_{e}=\frac{3}{2} p \psi i_{q}
$$

Equation (5) shows that the generator torque may be controlled by controlling the quadrature-axis current. It also shows that direct-axis current plays no role in torque production, so it can be regulated to zero to minimize resistive losses. A block diagram of the control scheme is shown in Fig. 3. The PI blocks indicate proportional-integral control, variables with a "*” superscript are setpoints, and SVPWM, $\mathrm{CCT}_{1}$, and $\mathrm{CCT}_{2}$ are defined below.

\section{A. Field-Oriented Control (FOC)}

Equation (1) is a nonlinear equation whose linear part can be written in the Laplace domain as

$$
\frac{i_{d}}{v_{d}}=\frac{1}{s L_{s}+R} .
$$

Standard techniques such as Bode or root locus can be used to design a controller for (6), then the nonlinear terms can be added to the output of the controller to find $\mathrm{v}_{\mathrm{d}}{ }^{*}$. This control scheme is called feedback linearization. The setpoint, $v_{d}^{*}$, passed to the rectifier is

$$
v_{d}^{*}=v_{d}{ }^{\prime}-L_{s} p \omega_{r} i_{q}
$$

where $v^{\prime}$ is the output of the PI controller shown in Fig. 3. Thus

$$
C C T_{1}=-L_{s} p \omega_{r} i_{q} .
$$

A controller for the generator torque can be designed in a similar way. Solving (3) for $i_{q}$ and substituting the result into (2) gives

$$
\frac{\tau_{e}(s)}{v_{q}(s)}=\frac{3 p \psi}{2 L_{s} s+2 R} .
$$

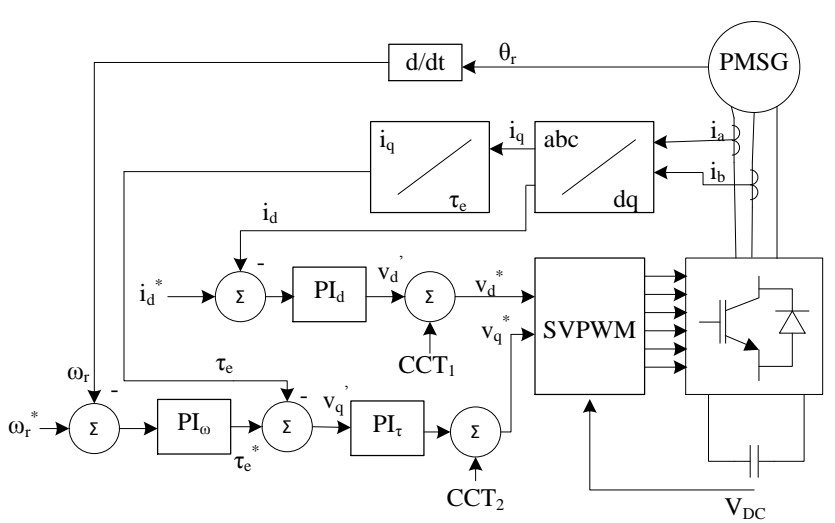

The second linearizing input term is then

$$
C C T_{2}=p \omega_{r}\left(\psi+L_{s} i_{d}\right) .
$$

In order to achieve speed control, a reference speed is supplied to the controller by a maximum power point tracking (MPPT) algorithm. As shown in Fig. 3, a slow outer loop with a third PI controller uses the speed error to determine a torque command. This PI controller has anti-windup protection. The controller gains are given in Table III.

\section{B. Space Vector Pulse-Width Modulation}

Once the controllers have provided reference voltages, $\left(v_{d}^{*}\right.$ and $v_{q}^{*}$ ) space vector pulse-width modulation $(S V P W M)$ is used to force the generator terminal voltages to those setpoints. It is assumed that the DC link voltage varies slowly so it can be assumed to be constant. Therefore, the active rectifier operates in very much the same way as a VSI: holding the DC link voltage constant, the controller fixes the output voltage of the generator. Although the generator produces a back EMF voltage proportional to the speed of rotation, the generator's resistance and inductance decouples the back EMF from the terminal voltage, which can be set by the rectifier because the DC link voltage is approximately constant.

SVPWM is based on the fact that there are six nonzero voltage vectors and two zero voltage vectors in the stationary reference frame that the rectifier can apply to the generator. The possible space vectors can be found by taking the Clarke transform of the line-to-neutral voltage of a six-step 3-phase bridge [19]. The voltage setpoint in the dq frame can be referred to the stationary reference frame through the inverse Park transform, rendering a complex space vector voltage setpoint, $V^{*}$ [20]. An example is shown in Fig. 4. SV1 and SV2 in Fig. 4 are space vectors that represent two different state combinations of the six insulated gate bipolar transistor $(I G B T)$ switches that make up the active rectifier. The rectifier switches between SV1, SV2 and a zero space vector quickly so that the average voltage applied to the generator is $\mathrm{V}^{*}$.

TABLE III

GENERATOR CONTROLLER GAINS

\begin{tabular}{|l|l|l|}
\hline Gain & 10 kW Turbine & 5 MW Turbine \\
\hline $\mathrm{K}_{\mathrm{P}}\left(i_{d}\right)$ & 0.27 & 0.5 \\
\hline $\mathrm{K}_{\mathrm{I}}\left(i_{d}\right)$ & 1.2 & 0.12 \\
\hline $\mathrm{K}_{\mathrm{P}}\left(\tau_{e}\right)$ & 0.07 & 0.01 \\
\hline $\mathrm{K}_{\mathrm{I}}\left(\tau_{e}\right)$ & 10.5 & 20 \\
\hline $\mathrm{K}_{\mathrm{P}}\left(\omega_{r}\right)$ & 900 & $3 * 10^{7}$ \\
\hline $\mathrm{K}_{\mathrm{I}}\left(\omega_{r}\right)$ & 12460 & $1.5^{*} 10^{7}$ \\
\hline
\end{tabular}

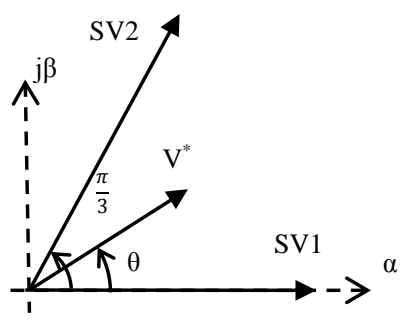

Fig. 3. Generator/Rectifier control scheme 
Fig. 4. SVPWM in sector I. Sector I consists of $0 \leq \theta \leq \pi / 3$.

The magnitude of $\mathrm{V}^{*}$ and the DC link voltage determine the modulation index as

$$
m \triangleq \frac{\left|V^{*}\right|}{V_{D C}} .
$$

Though Fig. 4 shows only sector I, the principles can be easily extended to the other sectors (combinations of IGBT's). This procedure has been well studied and details can be found in the literature [18] [21].

\section{GRID-SIDE CONTROL}

Because the systems use full converters, it is possible to achieve a great deal of control over the power that is injected into the grid. This control is performed in the synchronous reference frame and an LCL filter is used to limit the harmonics in the inverter output current. A phase-locked loop $(P L L)$, hosted on the inverter controller, is used to find the grid angle for the reference frame conversion [22]. A transformer is used to provide isolation between the VSI and the grid.

\section{A. LCL Filter}

A circuit diagram of one phase of the filter is shown in Fig. 5. An LCL filter is a better choice than a simple L filter in this application because better harmonic attenuation can be achieved with smaller components. However, LCL filters are inherently unstable due to resonance. One common way of damping that resonance is to place a resistor in series with the capacitor; this is called passive damping.

The LCL filter in this paper was designed according to the guidelines provided by Liserre et al. [23]. The component values selected are $\mathrm{L}_{1}=\mathrm{L}_{2}=0.574 \mathrm{mH}, \mathrm{C}=5.6 \mu \mathrm{F}, \mathrm{R}_{\mathrm{D}}=5 \Omega$. The guidelines depend on the switching frequency of the inverter which was chosen to be $7 \mathrm{kHz}$. Instead of using a discrete inductor for $\mathrm{L}_{2}$, the transformer was designed in such a way that the primary winding functioned as $\mathrm{L}_{2}$. Also, the resonant frequency was slightly higher than recommended by Liserre et al., but no resonance problems were seen in the results.

\section{B. Reactive Power Control}

One of the advantages of using a 3-phase full converter is the relative ease of controlling reactive power. Reactive power control is achieved in the reference frame attached to phase A of the grid voltage, called the synchronous reference frame.

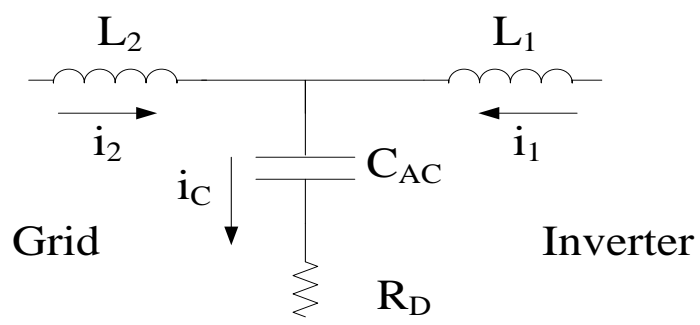

Fig. 5. One phase of an LCL filter with a passive damping resistor.
Assuming that the grid is relatively stiff and no fundamental current flows into $\mathrm{C}_{\mathrm{AC}}$, KVL loop equations can be written in the synchronous reference frame as

$$
v_{s q}=R i_{q}+\omega L i_{d}+L \frac{d i_{q}}{d t}+v_{g q}
$$

and

$$
v_{s d}=R i_{d}-\omega L i_{q}+L \frac{d i_{d}}{d t}+v_{g d},
$$

where $R$ is the combined series resistance of the filter and grid, $L$ is the combined series inductance of the filter and gird, $v_{s}$ is the inverter voltage, $v_{g}$ is the grid voltage, and $\omega$ is the angular frequency of the grid. It should be emphasized that the $\mathrm{d}$-axis and q-axis quantities in this section are in no way related to those in Section III. The grid voltage space vector is

$$
\left[\begin{array}{l}
v_{g d} \\
v_{g q}
\end{array}\right]=\left[\begin{array}{l}
0 \\
\widehat{V}
\end{array}\right],
$$

where $\widehat{V}$ is the peak phase voltage. It is assumed that the phase voltages are cosinusoidal. The active and reactive power outputs of the inverter can be written as

$$
P=\frac{3}{2} v_{g q} i_{q}
$$

and

$$
Q=\frac{3}{2} v_{g q} i_{d}
$$

respectively. $v_{g q}$ is assumed to be fixed because the grid is stiff so $Q$ can be completely controlled by controlling $i_{d}$. In a way very similar to the FOC of the generator, a reactive power controller can be designed using feedback linearization. $\mathrm{R}$ and $\mathrm{L}$ in (12) and (13) were considered to be that of the filter and the transformer for the purposes of feedback linearization. A block diagram for the controller is shown in Fig. 6 where $\mathrm{K}_{\mathrm{P}}=0.24$ and $\mathrm{K}_{\mathrm{I}}=0.85$ for the PI controller.

\section{DC Link Voltage Control}

It is common practice to use the q-axis grid current to control the DC link voltage [9] [10] [24] [25]. If the DC link voltage is constant, all of the power flowing out of the rectifier must then flow out of the inverter, less losses. The block diagram for the DC link voltage controller is shown in Fig. 7.

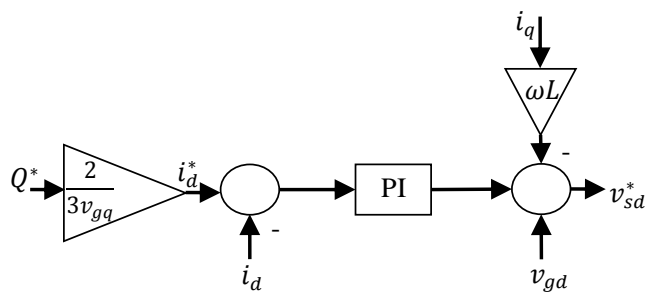

Fig. 6. Reactive power controller block diagram. 


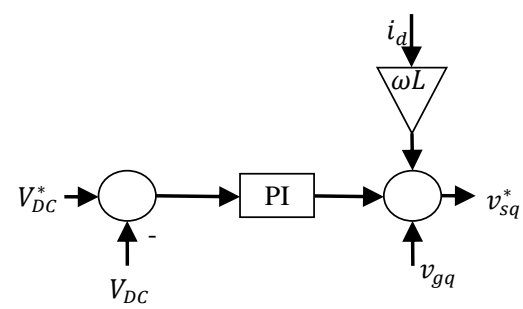

Fig. 7. DC link voltage controller block diagram. $\mathrm{L}$ is the total inductance of the filter.

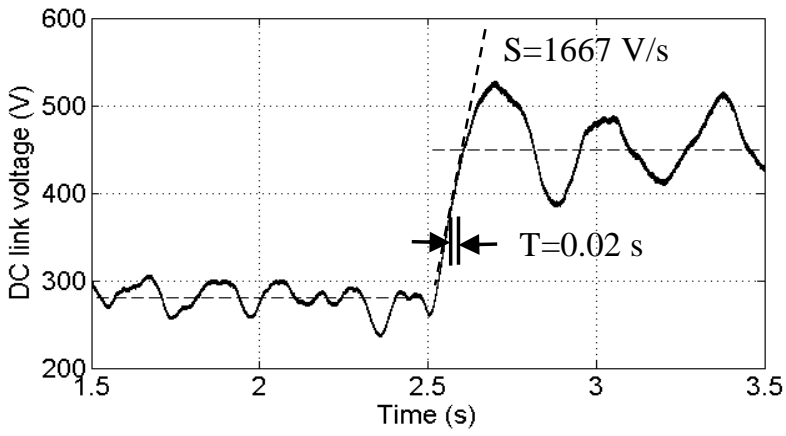

Fig. 8. DC link voltage process reaction curve for the $10 \mathrm{~kW}$ system.

Unlike reactive power control, there's no easy way to find a linearized transfer function for DC link voltage control. Therefore, the process reaction curve method, developed by Ziegler and Nichols, was used to find a starting point for tuning the PI controller [26]. Based on the process reaction curve (step response), the initial PI gains were determined as [27]

$$
K_{p}=\frac{-0.9}{S T}
$$

and

$$
K_{I}=\frac{0.3 K_{p}}{T},
$$

where $\mathrm{S}$ is the slope of the tangent line of the curve and $\mathrm{T}$ is the time between when the step command was issued and the process, DC link voltage in this case, began to change. The process reaction curve for the DC link voltage is shown in Fig. 8.

The initial gains were found with (17) and (18) and tuned until a satisfactory response was obtained. The final gains were $K_{P}=-0.56$ and $K_{I}=-0.32$. The gains are negative because this process exhibits reverse action, meaning an increase in the controller output $\left(i_{q}\right)$ produces a decrease in the process variable $\left(V_{D C}\right)$ [28]. SVPWM is used as described in Section III to realize $\mathrm{v}_{\mathrm{sd}} *$ and $\mathrm{v}_{\mathrm{sq}} *$.

\section{RESULTS}

\section{A. $10 \mathrm{~kW}$ System Model Results}

Simulations that include all of the tools, components, and controllers discussed above have been completed with operating conditions that are as realistic as possible. Fig. 9 shows a comparison between the power curve for the Bergey Excel 10 as of its Small Wind Certification Council (SWCC) certification tests in 2011 and the power curve found with simulations as described in this paper, [29]. The results in Fig. 8 show that the power curve found with the model presented in this paper is a reasonable approximation of the measured one. It has been documented that the FAST model turbine spins too fast at and above $10 \mathrm{~m} / \mathrm{s}$ due to the lack of blade tip torsion in FAST [7]. Despite this, the power output was somewhat depressed between 11 and $13 \mathrm{~m} / \mathrm{s}$ because of greater $i^{2} R$ losses, which only a detailed model such as this accounts for.

Electromechanical simulations were performed to show the high level of detail included in the models in this work, as well as the and broad range of variables they are capable of simulating. Fig. 10 shows the wind input used in the simulations that produced the figures in this subsection. Figs. 12 - 15 show various electrical and mechanical variables captured during the simulation. The first 10 seconds of the simulation were disregarded for initialization of the model.

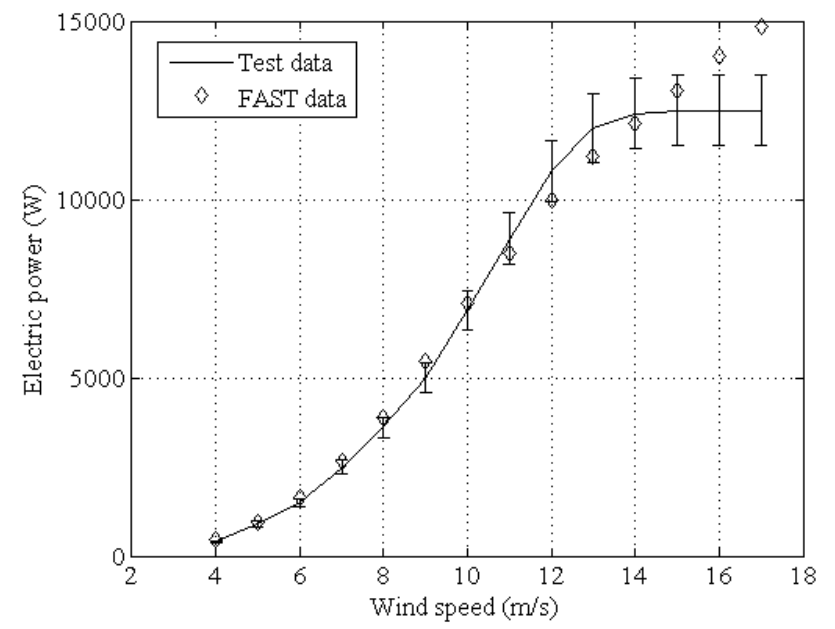

Fig. 9. Power curve comparison between measured Bergey Excel 10 data and simulated data for the $10 \mathrm{~kW}$ system.

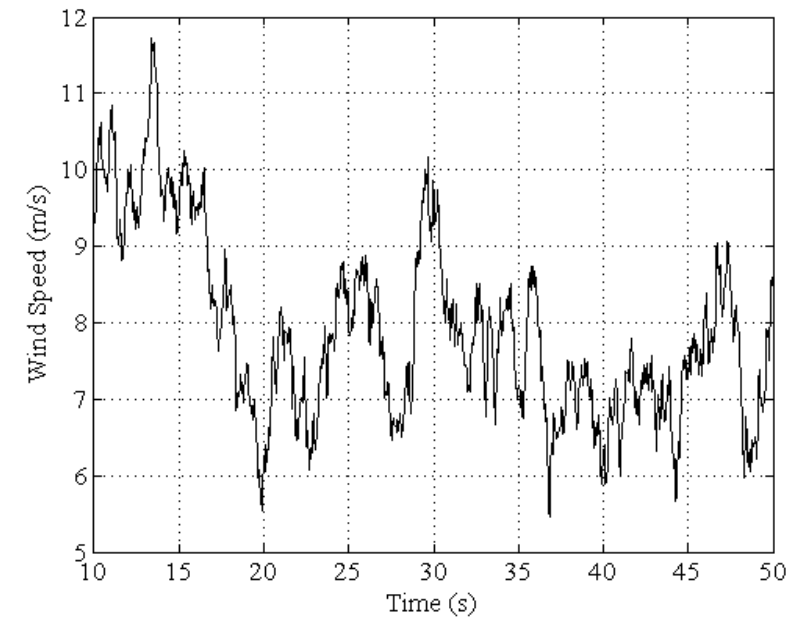

Fig. 10. Wind input used in $10 \mathrm{~kW}$ simulations. 

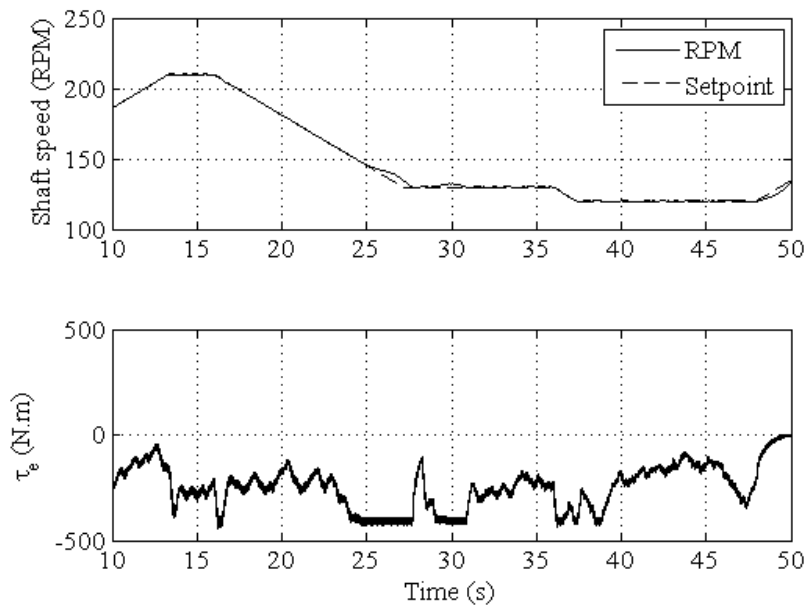

Fig. 11. Speed and generator torque for the $10 \mathrm{~kW}$ system.
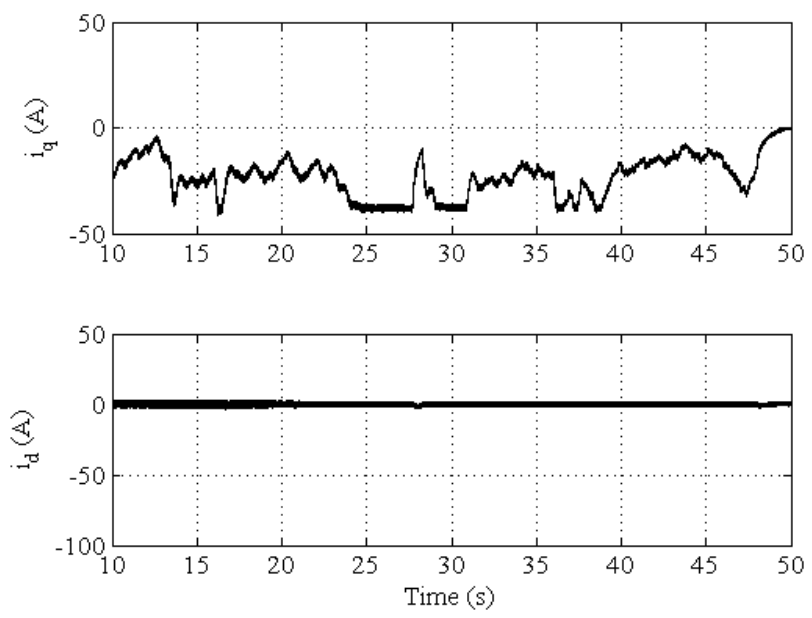

Fig. 12. D-axis and q-axis current in the $10 \mathrm{~kW}$ generator.
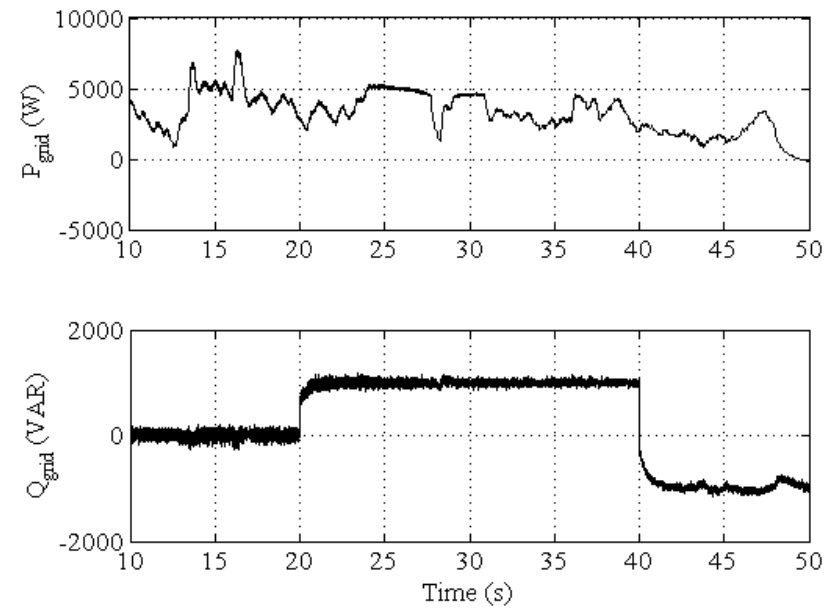

Fig. 13. Real and reactive power injected onto the grid for the $10 \mathrm{~kW}$ system.

Fig. 11 shows the speed and torque during the simulation. Clearly the speed follows the setpoint very closely, and the torque varies with approximately the same profile as the wind. Negative torque corresponds to generator action in both models.

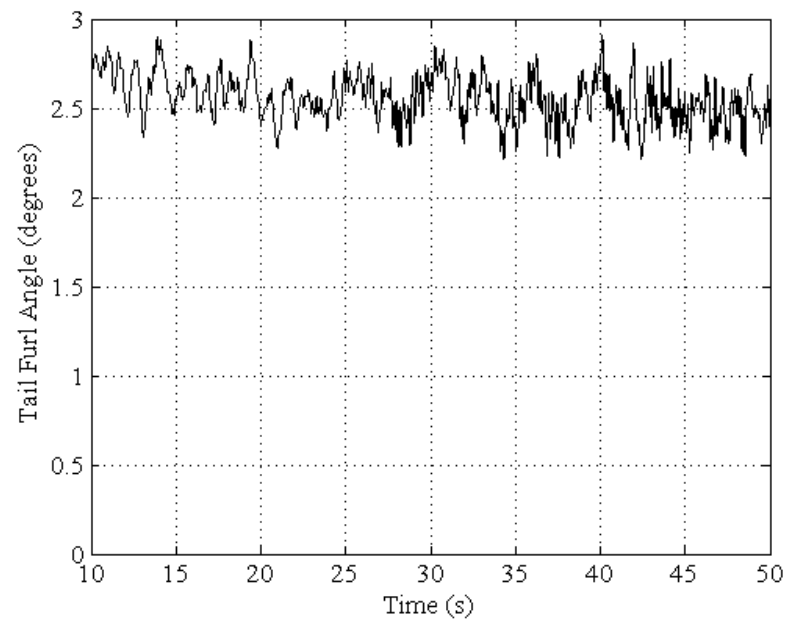

Fig. 14. Tail furl angle for the $10 \mathrm{~kW}$ system.

Fig. 12 shows that the generator current control scheme from Fig. 3 works properly. The d-axis current is controlled to zero to minimize losses in the generator, while the q-axis current follows the torque as predicted by (5).

Fig. 13 shows the real and reactive power produced by the system. As expected, the real power (P) approximately follows the wind profile, reaching a peak of $7.5 \mathrm{~kW}$ at $11.75 \mathrm{~m} / \mathrm{s}$. Fig. 13 also shows the model's reactive power control in action as it is arbitrarily controlled from 0 to $1 \mathrm{kVAR}$ to $-1 \mathrm{kVAR}$.

Finally, the tail furl angle of the turbine is shown in Fig. 14. This is just one example of turbine, tower, and blade variables that can be simulated by FAST. A complete list of those variables can be found in [17].

\section{B. 5 MW System Model Results}

Fig. 15 shows the power curve of the $5 \mathrm{MW}$ system model compared to that for the REpower $5 \mathrm{MW}$ machine. The $5 \mathrm{MW}$ turbine model, the NREL 5 MW turbine, is based partly on the REpower machine. Clearly, from Fig. 1ㅁ, the 5 MW model agrees very closely with the published power curve of the REpower machine.

Fig. 16 shows the wind input used for the simulation results shown in this subsection.

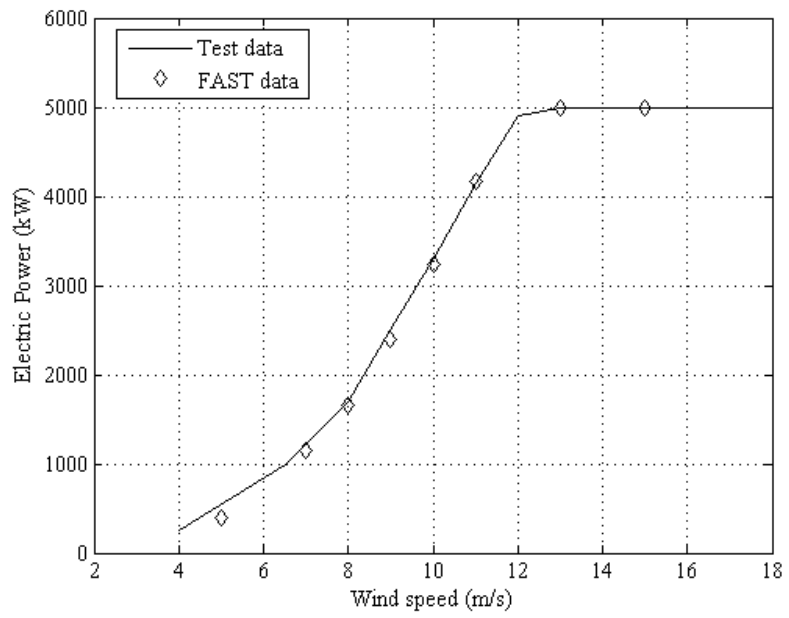

Fig. 15. Power curve comparison between measured REpower 5MW data and simulated data for the $5 \mathrm{MW}$ system. 


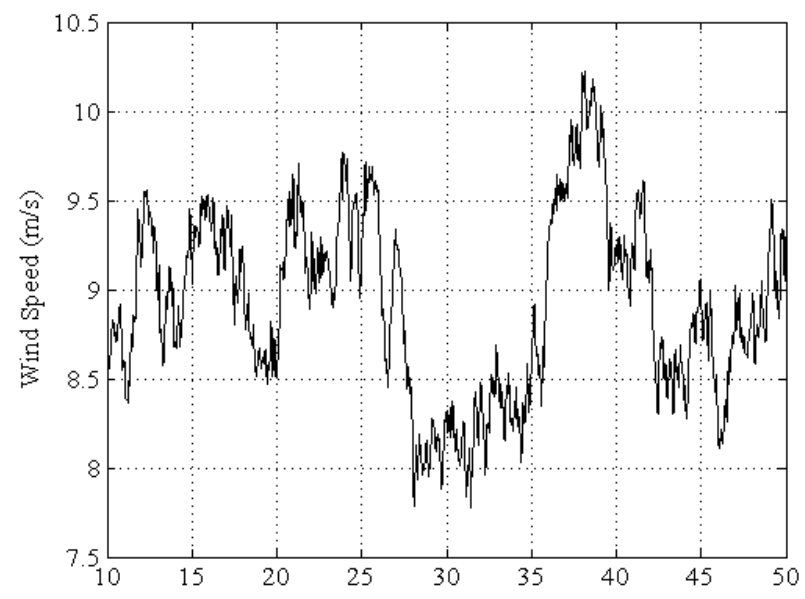

Fig. 16. Wind input used in the 5 MW system simulations.
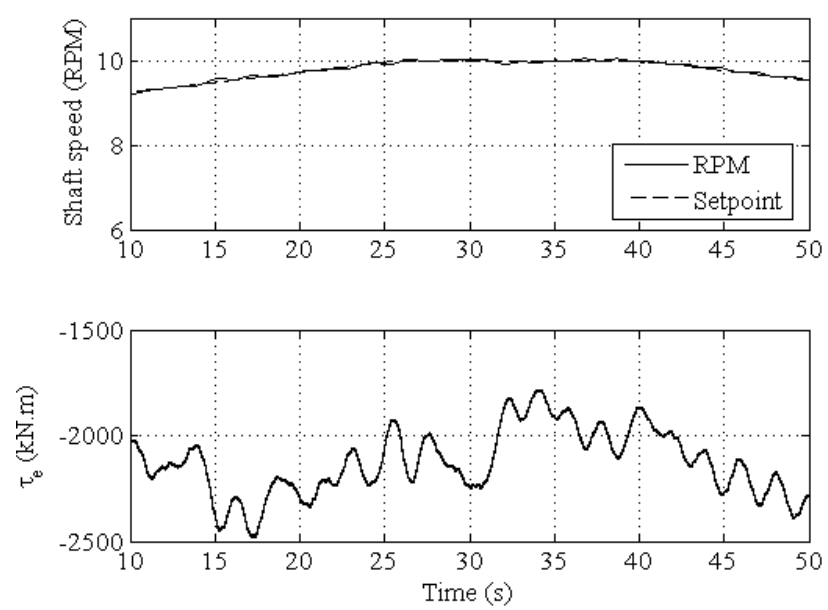

Fig. 17. Power curve comparison between measured REpower 5MW data and simulated data for the $5 \mathrm{MW}$ system.
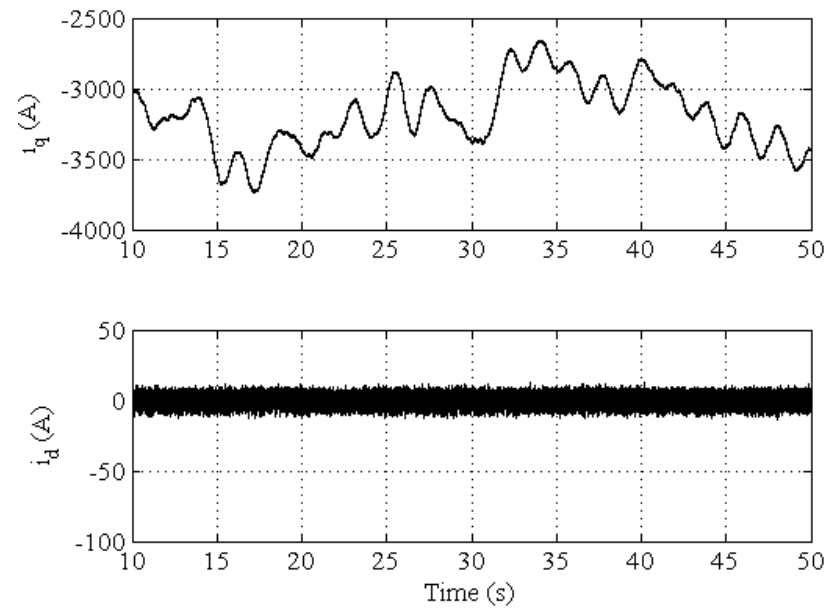

Fig. 18. D-axis and q-axis current in the $5 \mathrm{MW}$ generator.
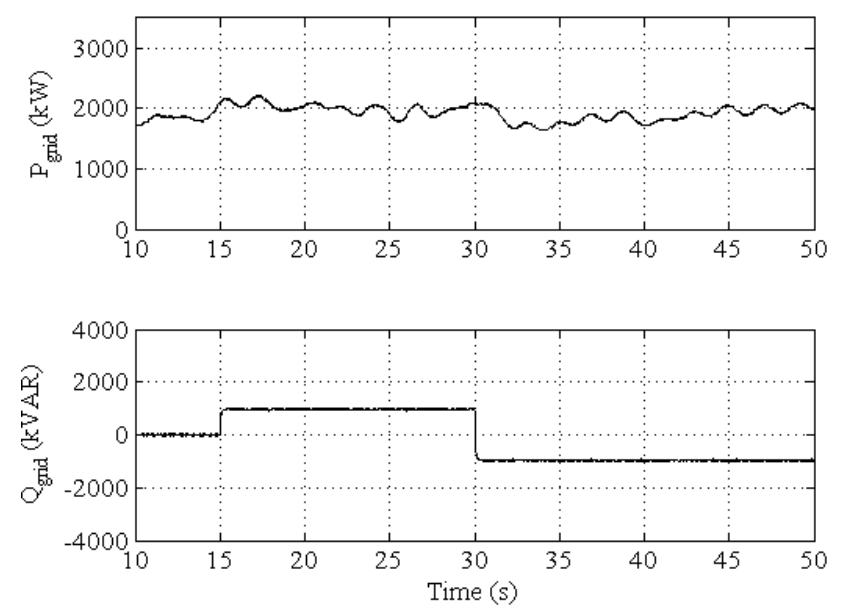

Fig. 19. Real and reactive power injected onto the grid for the $5 \mathrm{MW}$ system.

Fig. 17 shows the speed and torque of the generator. As expected, the torque approximately follows the wind as the torque controller works to maintain the proper speed. The speed matches its setpoint well throughout the simulation.

Fig. 18 shows the $\mathrm{d}$-axis and $\mathrm{q}$-axis current during the simulation. Like Fig. 12 for the $10 \mathrm{~kW}$ system, the d-axis current is well regulated to zero, and the q-axis current is used to produce all of the generator torque.

Finally, Fig. 19 shows the real and reactive power output of the system onto the grid. The real power follows the same basic trend as the wind, while the reactive power is arbitrarily controlled to show the capability of the model and validity of the controllers developed above. The reactive power is controlled to \pm 1 MVAR, which represents 0.9 leading and lagging power factor at an output of $2 \mathrm{MW}$.

\section{CONCLUSIONS AND FUTURE WORK}

Highly detailed models have been developed for two of the major classes of wind turbines: residential-scale and utilityscale. The models are the first to couple the high-detail, highaccuracy mechanical and aeroelastic simulation capabilities of FAST to full electrical system models for PMDD wind turbines. Very specific information on the development of the models has been provided, especially on the electrical system, so that they may be easily reproduced and used in wind turbine design and research. Some results have been presented that show comparisons between the power curves obtained with the models presented in this paper and those obtained experimentally. The models' power curves match the experimental ones very closely, which shows the validity of the models. Other results have also been presented that show some of the high level of detail the models are capable of producing.

Future work includes further validation of the models against experimental data, as well as developing a similar model for mid-size $(150-750 \mathrm{~kW})$ PMDD wind turbines.

\section{ACKNOWLEDGMENT}

The authors gratefully acknowledge Tod Hanley at Bergey 
Windpower for his contributions to this work.

\section{REFERENCES}

[1] P. Carlin, A. Laxson and E. Muljadi, "The History and State of the Art Variable-Speed Wind Turbine," Wind Energy, vol. 6, no. 2, pp. 129159, Feb. 2003.

[2] K. Ding, X. Bian, H. Liu and T. Peng, "A MATLAB-Simulink-Based PV Module Model and Its Application Under Conditions of Nonuniform Irradiance," IEEE Trans. Energy Convers., vol. 27, no. 4, pp. 864-872, Dec. 2012.

[3] R. Fadaeinedjad, M. Moallern and G. Moschopoulos, "Simulation of a Wind Turbine With Doubly Fed Induction Generator by FAST and Simulink," IEEE Trans. on Energy Convers., vol. 23, no. 2, pp. 690700, June 2008.

[4] B. Beltran, T. Ahmed-Ali and M. Benbouzid, "High-order sliding-mode control of variable-speed wind turbines," IEEE Trans. Ind. Electon., vol. 56, no. 9, pp. 3314-3321, 2009.

[5] S. B. Krishna and S. V. Reeba, "Simulation of Wind Turbine with Switched Reluctance Generator by FAST and Simulink," in 10th National Conference on Technological Trends, Trivandrum, 2009.

[6] J. Zhang, M. Cheng and Z. Chen, "Design of wind turbine controller by using wind turbine codes," in Proc. 2008 International Conference on Electrical Machines and Systems.

[7] D. Corbus and M. Meadors, "Small Wind Research Turbine Final Report," National Renewable Energy Laboratory, Golden, CO, Oct. 2005.

[8] A. Hemeida, A. A. Farag and O. A. Mahgoub, "Modeling and Control of Direct Driven PMSG for Ultra Large Wind Turbines," World Academy of Science, Engineering and Technology, vol. 59, pp. 918-924, 2011.

[9] M. Chinchilla, S. Arnaltes and J. Burgos, "Control of permanent-magnet generators applied to variable-speed wind-energy systems connected to the grid," IEEE Trans. Energy Convers., vol. 21, no. 1, pp. 130-135, March 2006.

[10] S. Muyeen, "A Variable Speed Wind Turbine Control Strategy to Meet Wind Farm Grid Code Requirements," IEEE Trans. Power Syst., vol. 25, no. 1, pp. 331-340, 2010.

[11] T. Hanley, Personal Communication, 2012.

[12] J. Jonkman, "Modeling of the UAE Wind Turbine for the Refinement of FAST_AD," National Renewable Energy Laboratory, Golden, CO, Dec. 2003.

[13] J. Jonkman, S. Butterfield, W. Musial and G. Scott, "Definition of a 5MW Reference Wind Turbine for Offshore System Development," NREL, Golden, CO, 2009.

[14] M. Buhl, April 2001. [Online]. Available: Available: http://wind.nrel.gov/designcodes/preprocessors/modes/.

[15] B. J. Jonkman, "TurbSim User's Guide: Version 1.50," National Renewable Energy Laboratory, Golden, Co, Sept. 2009.

[16] P. Moriarty and A. C. Hansen, "AeroDyn Theory Manual. NREL/EL500-36881," National Renewable Energy Laboratory, Golden, Co, 2005.

[17] J. M. Jonkman and M. L. B. Jr., FAST user's guide, NREL/EL-50029798, Golden, CO: National Renewable Energy Laboratory, 2005.

[18] P. Krause, O. Wasynczuk and S. Sudhoff, Analysis of Electric Machinery and Drive Systems, 2nd ed., Piscataway, NJ: IEEE Press, 2002 , p. 265 , p. 507

[19] W. C. Duesdterhoeft, M. W. Schulz and E. Clarke, "Determination of Instantaneous Currents and Voltages by Means of Alpha, Beta, and Zero Components," Transactions of the American Institute of Electrical Engineers, vol. 70, no. 2, pp. 1248-1255, Jul. 1951.

[20] R. Park, "Two-Reaction Theory of Synchronous Machines Generalized Method of Analysis, Part I," AIEE Transactions, vol. 48, pp. 716-727, July 1929.

[21] D. Holmes and T. Lipo, Pulse Width Modulation for Power Converters, IEEE, 2003.
[22] C.-C. Hsieh and J. Hung, "Phase-locked loop techniques - A survery," IEEE Trans. Ind. Electron., vol. 43, no. 6, pp. 608-615, 1996.

[23] M. Liserre, S. F. Blaabjerg and Hanson, "Design and Control of an LCL-Filter-Based Three-Phase Active Rectifier," IEEE Trans. Ind. App., vol. 41, no. 5, pp. 1281-1291, Sept.-Oct. 2005.

[24] R. Teodorescu and F. Blaabjerg, "Flexible control of small wind turbines with grid failure detection operating in stand-alone and gridconnected modes," IEEE Trans. Power Electron., vol. 19, no. 5, pp. 1323-1332, Sept. 2004.

[25] S. Dehghan, M. Mohamadian and A. Varjani, "A New Variable-Speed Wind Energy Conversion System Using Permanent-Magnet Synchronous Generator and Z-Source Inverter," IEEE Trans. Energy Convers., vol. 24, no. 3, pp. 714-724, Sept. 2009.

[26] J. Ziegler and N. Nichols, "Optimum Settings for Automatic Controllers," Trans. ASME, vol. 64, pp. 759-768, 1942.

[27] G. Franklin, J. Powell and A. Emami-Naeini, Feedback Control of Dynamic Systems, Upper Saddle River, NJ: Pearson Prentice Hall, 2006, p. 198-199.

[28] C. D. Johnson, Process Control Instrumentation Technology, Englewood Cliffs, NJ: Prentice Hall, 1993, p. 361.

[29] SWCC, 2011. [Online]. Available: Available: http://www.smallwindcertification.org/wp-content/newuploads/2011/11/Summary-Report-10-12.pdf.

\section{BIOGRAPHIES}

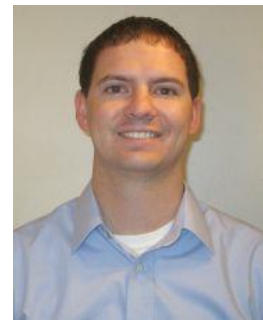

David S. Ochs (S '09) received the B.S. and M.S in electrical engineering from Kanas State University in Manhattan, Kansas. He is currently designing controls and diagnostics for hybrid and electric vehicles in Torrance, CA. His research interests include power electronics, control of ac motor drives, and thermal management of power electronics.

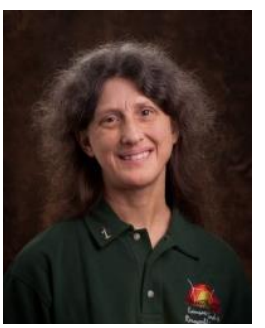

Ruth Douglas Miller (S '83 M '90 SM '00) received the B.Sc in electrical engineering from Lafayette College, PA, in 1984, and M.S. and Ph.D. degrees in electrical engineering from the University of Rochester in 1985 and 1990 respectively. Since 2007 she has been working in the areas of power electronics for wind and solar energy, wind resource assessment and the integration of wind energy into the grid. She directs the Kansas Wind Applications Center at KSU

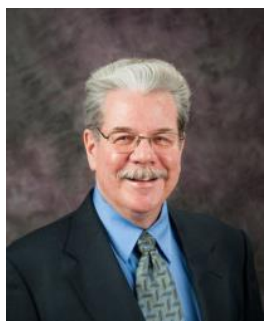

Warren N. White received his B.Sc. in electrical engineering with honors from Tulane University in 1974, his Masters in electrical power engineering from Rensselaer Polytechnic Inst. in 1977, and the $\mathrm{Ph} . \mathrm{D}$. in mechanical engineering from Tulane University in 1985. Since 1985, he has been with the mechanical and nuclear engineering department at KSU. His main research interests consists of nonlinear control theory, underactuated mechanical systems, wind turbine control, power equipment rejected heat, and control education. 